Western University Scholarship@Western

1981

\title{
A Small Macro-Model of the Post War United States
}

David Laidler

Brian Bentley

Follow this and additional works at: https://ir.lib.uwo.ca/economicsresrpt

Part of the Economics Commons

Citation of this paper:

Laidler, David, Brian Bentley. "A Small Macro-Model of the Post War United States." Department of Economics Research Reports, 8101. London, ON: Department of Economics, University of Western Ontario (1981). 
ISSN: $\quad 0318-725 \mathrm{X}$

ISBN: $\quad 0-7714-0245-7$

RESEARCH REPORT 8101

A SMALL MACRO-MODEL OF THE POST WAR

UNITED STATES*

by

David Laidler and Brian Bentley

January, 1981

*We are grateful to the SSHRCC for Financial Support, and to Charles Adams, Michael Burns, Jeff Carmichael, Peter Jonson, Bill Poole and Rob Trevor for helpful comments on an earlier paper dealing with this model.

Department of Economics Libran

JAN 261981

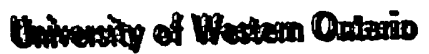




\section{INTRODUCTION}

Some years ago, one of us developed a small scale model of the interaction of output and the inflation rate in a closed economy. (See Laidler 1975, Ch.7) The model in question was analytically simple, consisting of but three equations, and was therefore well adapted to classroom use, even at the undergraduate level. However it also turned out to have considerable empirical content when tested against data generated by the post-Korean war United States. Thus, unlike the vast majority of small analytic models presented to undergraduate (and graduate for that matter) macroeconomics classes, it could be defended against charges of "oversimplification" by noting that, though many important elements of the real world were omitted, enough key features seemed to have been left in to ensure that the model in question was nevertheless of some: practical relevance.

Even so, the model was extremely simple, and too simple for many tastes. It consisted of a demand for real money balances function, log. linear in the level of real income, but containing no opportunity cost variable, an expectations augmented Phillips curve, and an equation defining the expected rate of inflation as being determined by a first order error learning process. It was driven by but two exogenous variables, the nominal money supply, and the "full employment" or "natural" level of output, which was for empirical purposes determined by a log. linear time trend. Its real side was thus a "vertical LM curve" short run income determination model that permitted nothing but money to influence the level of aggregate demand. Indeed the only source of variation in the velocity of circulation lay in the possibility that the real income elasticity of demand for money might differ from unity, 
so that velocity would vary with the manner in which money income fluctuations were divided between real income and the price level.

In this paper, we present a more sophisticated version of the same type of model. Though it retains enough simplicity to make it potentially useful as a teaching device, the most objectionable features of its prototype have be removed. First, an opportunity cost variable is permitted to enter the demand for money function, and as is only fitting in a model which seeks to deal with price behaviour, the role of the expected rate of inflation in determining the value of this opportunity cost is explicitly recognised. Second, the structure of the model is such that variables other than the quantity of money are permitted to influence the level of aggregate demand. Government expenditure, taxes, and variations in what we may loosely term the marginal efficiency of capital, all have a potential role to play. Third, interest rate variables, which were completely omitted from the earlier model, are included in this one as endogenous variables, determined within the system. The "full employment" level of income is still however treated as exogenous in what follows, but this is hardly an uncommon property for a short run macro-model.

As did the prototype model, this one turns out to have considerable empirical content, as the bulk of this paper will be devoted to demonstrating. We will show that the model fits post-Korean war United States data reasonably well, and that it is rather robust in the face of an extension of the data back to 1946. Moreover, we shall also show that it fits this longer set of data at least as well as Robert J. Barro's "new-classical model" of price and output determination (See Barro 1978), despite being in most respects a simpler 
structure. Before turning to these empirical results, we will present the basic model for which they have been generated.

\section{THE MODEL}

Our model consists of six equations, determining output, the demand for money, the inflation rate, a nominal interest rate, a real interest rate, and the expected inflation rate. The first of these is the most complex, being in effect the reduced form of a simple Keynesian income-expenditure system. ${ }^{1}$ Aggregate output is here treated as a passive veriable that responds immediately to satisfy aggregate demand, which therefore becomes the key variable in the system. Aggregate demand in turn consists of private sector expenditure and government expenditure. Real government expenditure on goods and services, $G$, is treated as exogenous, while real private sector expenditure, $E$, is thought of as being determined along the following lines. With $Y *$ real permanent income, $R$ the real rate of interest, $T$ the tax rate, Ms the quantity of nominal money supplied, Md the quantity of nominal money demanded in the "long run" (the term will be more precisely defined in a moment), and subscripts -1 referring to time lags, we write

$$
E=k\left[R_{-1}, T_{-1}, \frac{M s}{M d}-1\right] Y *
$$

So that, with $\mathrm{Y}$ real current output, we have

$$
\mathrm{Y}=\mathrm{G}+\mathrm{k}[] \mathrm{Y} \text { * }
$$


If we treat the term in parentheses in equation (1) as having the form

$$
\mathrm{R}_{-1}^{\alpha^{\prime}}{ }^{6} \cdot \mathrm{T}_{-1}^{\alpha^{\prime}} 3 \cdot \frac{\mathrm{Ms}}{\mathrm{Md}}_{-1}^{\alpha^{\prime}}{ }_{1}
$$

then a $\log$ Inear approximation to equation (2) is given by

$$
y=\alpha_{1}(m s-m d)_{-1}+\alpha_{3} t_{-1}+\alpha_{4} g+\alpha_{6} r
$$

In equation (i), which is the output equation of our model, the variables have the following meanings:

$y: \log \frac{Y}{Y^{*}}$ or the transitory component of the logarithm of output.

t: the deviation of the logarithm of the tax rate from its steady state value.

g: the deviation of the logarithm of government expenditure from its steady state value.

r: the deviation of the real rate of interest from its steady state value. ms: the logarithm of the money supply.

md: the logarithm of the quanity of money demanded in the "long run".

If we argue that, in the steady state, the supply and long run demand for money are equal to one another, then it will be seen that the term (ms - md) also measures the deviation of that variable from its steady state value.

As to the parameters of equation (i), these are to be interpreted as follows 


$$
\begin{aligned}
& \alpha_{1}=k \alpha_{1}^{\prime} \\
& \alpha_{3}=k \alpha_{3}^{\prime} \\
& \alpha_{4}=(1-k) \\
& \alpha_{6}=k \alpha_{6}^{\prime}
\end{aligned}
$$

As must be apparent from the above definitions of the variables and parameters, equation ( $i$ ) is obtained by linearising equation ( 1 ) about the steady state values of the logarithm of its variables. ${ }^{2}$ In deriving that equation, we have postulated that the steady state value of national income is given by $Y^{*}$. This involves us in treating this "natural" level of output as equivalent to the "permanent" real income variable that influences private sector expenditure. If output always converges upon the same natural level, than its value represents an expectation of income that is, in the "long run", rational, so this property of equation (3) is by no means indefensible. It is, however worth explicitly noting that this does not mean that complete long run "crowding out" is imposed upon this equation. $\mathrm{Y}^{*}$ could vary with the steady state values of $G$ and $T$. However, our model has nothing to say about this matter. It deals only with the short run effects of fiscal policy upon output. ${ }^{3}$ Thus equation (i) leaves fiscal policy's temporary effects on real Income open to empirical investigation, while the same may be said of the influence of interest rate fluctuations. Moreover, the possibility that shorter run fluctuations in output might themselves influence expenditure, thus generating a multiplier process, could easily be allowed for by adding a lagged transitory income term to the right hand side of equation (i). Its absence there does not reflect any a priori judgement on our part. Indeed we tested for the Importance of this variable in the course of our empirical 
work, but, with the annual data that we used, found no role for it to play. ${ }^{4}$

Probably the most unusual argument in equation ( 1 ) is the term (ms - md), though there are by now several precedents for including this "real balance effect" term in such an equation. ${ }^{5}$ Recall to begin with that the term md represents the logarithm of the "long run" quantity of money demanded. By this phrase we mean exactly what Gregory Chow (1966) and others who have written about such matters since he did have meant, namely the quantity of money that agents would hold, given the values taken by the arguments in the demand function, if there were no costs involved in instantaneously adjusting cash holdings to their desired level. The term (ms - md) represents the difference between the quantity of money in circulation, which therefore must be held by agents, and this long run demand for money.

The proposition that there might be a difference between the amount of money in circulation at a particular moment and the long run demand for money at that same moment is a commonplace of the literature on the demand for money. It is one of the premises upon which the conventional "adjustment cost" argument for including a lagged dependent variable in the function when modelling the "short run" demand for money is based. However, we would argue that, in an economy in which the nominal money supply is exogenous to the variables determining the demand for money, it is incorrect to postulate that the money supply adjusts slowly towards a long run target value; but that Is just what the usual adjustment cost based lagged dependent variable formulation of the demand for money function implicitly does. If the exogenous money supply differs from the quantity of money that agents wish to hold, then their attempts to adjust their cash holdings must cause their expenditure 
flows to take a value different from those implied by whatever values other factors affecting expenditure might take. In short, there is a real balance effect on expenditure when the economy is "off" its long run demand for money function, and the term $\alpha_{1}(m s-m d)$ in equation ( $i$ ) represents an attempt to capture it in simple algebraic terms.

Had the phrase not already been appropriated by the new-classical economists, and given a different meaning, it would be convenient to refer to the term (ms - md) as "unanticipated money": it does after all refer to the amount of money in circulation to which the arguments of the long run demand for money function have not adjusted. Moreover, the inclusion of this term In an output determining equation amounts to saying that "unanticipated money leads to changes in output". Again the phrase has a familiar ring, but it does not here mean quite what it does in new-classical economics. For example, In the work of Barro (1978), unanticipated money is money to which the price level has not fully and immediately adjusted, and it influences output by way of further effects on the general price level that individual agents misread as reflecting relative price changes. For Barró, therefore, all observations are "on" the demand for money function. For us "unanticipated money" refers to money to which the arguments of the long run demand for money function have not adjusted, and its effect on output comes about not through any supply side response to price changes, but by way of a real balance effect on expenditure to which output adjusts along orthodox textbook Keynesian Iines.

The long run demand for money in our model is given by the following, quite conventional, log. linear relationship 


$$
M_{d}=\delta_{\partial}+\delta_{1} y^{*}+\delta_{2} r_{n}+p
$$

The only variables here not yet defined are $r_{n}$, which is the logarithm of some nominal interest rate that represents the opportunity cost of holding money, $p$ the log. of the general price level, and $y *$ the log. of $Y *$.

The next equation to be discussed is that determining price level behaviour. Our initial choice here is a conventional expectations augmented PhIllips curve which the reader should not interpret as being derived from any sort of "aggregate supply" function analysis. We have already used a very simple Keynesian $45^{\circ}$ aggregate supply curve in deriving our output equation, and cannot now resort to introducing a second such relationship, Inconsistent with the first, into our model. However, as is well known, there exists an alternative explanation of price-output interaction in the literature and that alternative is a natural supplement to our output equation. It treats the Phillips curve as a price setting equation. 6 Where $\Delta p$ is the first difference of the logarithm of the price level, $\Delta p e$ the expected inflation rate, and $y$ the deviation of the logarithm of income from its "natural" level, and hence a proxy for excess demand, we write

$$
\Delta p=B y_{-1}+\Delta p_{-1}^{e}
$$

This equation supplements equation (1) in an extremely straightforward manner. The latter determines the level of aggregate demand, and therefore actual output, while in equation (iii) output influences prices and hence feeds back by way of its role in the demand for money function into the determination of the level of output in the subsequent period. However, as one of 
us has noted elsewhere (Laidler 1975, Ch. 1) firms as well as households hold cash balances, and if one regards excess money balances as giving a signal to firms to increase their output, one should entertain the possibility that they would respond to that signal by changing their prices as weil. In that case one might regard output and prices as responding together to excess cash balances rather than in the mechanical sequence implied by the foregoing discussion. The implication of this would be that, rather than have an output variable in equation (iii), one should instead include the term $\left(m_{8}-m_{d}\right)$ as having a direct influence on the inflation rate. Of course the presence of such a term in our output equation ensures that the two formulations are closely related to one another, but even setting matters of timing aside, they are not quite identical because of the presence of other variables in equation (i) determining output.

Be that as it may, Jonson and his associates report good results with an $\left(m_{s}-m_{d}\right)$ term in the price equation of the RBA 79 model of the Australian economy. (See Clements and Jonson 1979.) Thus, as an alternative to equation (111), we also experimented with the following equation:

$$
\Delta \mathrm{p}=\beta_{1}\left(\mathrm{~m}_{\mathrm{s}}-\mathrm{m}_{\mathrm{d}-1}\right)+\Delta \mathrm{p}_{-1}^{\mathrm{e}}
$$

As we shall see in due course, either expression performs well, with the latter giving, on the whole, marginally better results.

Equation (i) contains two interest rate variables, a nominal rate representing the opportunity cost of holding money, and a real interest rate that is thought of as exerting a negative influence on the flow of expenditure. 
In order to make these variables endogenous, we must first of all say something about the factors that influence the interaction of real and nominal interest rates. According to Irving Fisher, the nominal interest rate ought to equal the real interest rate plus the expected rate of inflation, at least on assets that are otherwise similar. Thus we write, using capital letters to denote natural values of the variables

$$
\mathrm{Rn}=\mathrm{R}+\Delta \mathrm{p}^{\mathrm{e}}
$$

With our Interest rate variables thus linked by equation (iv), we need only to add an equation to determine one of them in order to complete our mode1. ${ }^{7}$ As the reader will recall, in deriving equation ( 1 ), we postulated the existence of a steady state value for the real rate of interest, arguing that temporary deviations of the rate from this steady state value would Influence aggregate demand. We would suggest that it is reasonable to think of this steady state value as being determined by the underlying "long run" forces of "productivity and thrift". One factor that might be expected to Influence the real rate of interest in the short run, to drive it away from Its long run equilibrium value, is surely the existence of an excess supply or demand for money. If the economy as a whole is trying to adjust its money holdings towards some target value determined by the long run demand for money function, then existing assets as well as currently produced goods and services would presumably be one of the objects of the resulting flows of expend1ture. To the extent that such expenditure flows had the effect of driving the current price of such assets, and hence the interest rate, away from Its steady state value, variations in the real rate of interest in our equation (5) would in fact be capturing a further channel of influence on 
expenditure of the quantity of money, rather than representing another, Independent, factor affecting aggregate demand.

Thus we postulate that the real rate of interest might be determined by an equation such as

$$
R=\phi_{0}+\phi_{1}(\mathrm{~ms}-\mathrm{md})+\rho
$$

where the parameter $\phi_{0}$ is an estimate of the steady state value of the real rate of interest, where $\phi_{1}$ is expected to be negative and where $\rho$ is a"catchall" vector of other influences on the real rate of interest, representing fluctuations in the marginal efficiency of capital.

Finally, we need an equation to determine the expected rate of inflation, and here we use the error learning hypothesis. We make no apology for this, because although the hypothesis in question is much criticised for its mechanical nature, it does perform well empirically. Moreover, its use imparts to our model an element of Inertia in price level behaviour that commentators as otherwise diverse in their views as Tobin (1980) and Cagan (1980) have each argued is an important factor in the inflationary process In modern economies. Furthermore, the fact that we include the expected inflation rate in both our price equation and that linking nominal with real Interest rates means that, in effect, when it comes to estimating our model, we will be using the information contained in the interest rate variables to discipline the estimation of the parameter of our error learning process. Though this step will hardly satisfy exponents of the rational expectations .hypothesis, it does at least introduce an element of forward looking behaviour 
into our treatment of expectations. Thus the expectations equation which completes our model is given by

$$
\Delta p^{e}=d \Delta p+(1-d) \Delta p_{-1}^{e}
$$

Now, if our model was to be estimated one equation at a time, the foregoing discussion would suffice to describe it. However, the reader will have noted that, although it is the logarithms of the two interest rate variables that appear in equations (i) and (ii), it is the natural values of these variables that appear in the Fisher Hypothesis embodied in equation (iv) and the natural value of the real rate of interest that we have written as the dependent variable of equation $(v)$. Because we wish to estimate our model as a "complete" system, using full information techniques in order to exploit the many links between its components, this will not do. Hence we use the natural value of interest rates throughout the model, approximating the log. linear relationships with semi-logarithmic formulations wherever appropriate. This step ensures that the model as a whole is a linear one and hence renders it easily amenable to purely qualitative analysis. Later we will report the results of such single equation estimates designed to check on the extent to which the approximation under discussion here distorts our results.

The model as a whole may now be written as follows:

$$
\begin{aligned}
& y=\alpha_{1}\left(m_{s}-m_{d}\right)-1+\alpha_{3} t-1+\alpha_{6}^{1}\left(R_{-1}-\phi_{0}\right) \\
& m_{d}=\delta_{0}+\delta_{1} y^{*}+\delta_{2}^{1} R n+p
\end{aligned}
$$




$$
\begin{aligned}
\Delta p & =\beta_{0} y_{-1}+\Delta p_{-1}^{e} \\
\Delta p & =\beta_{1}\left(m_{s}-m_{d}\right)_{-1}+\Delta p_{-1}^{e} \\
R n & =R+\Delta p e \\
R & =\phi_{0}+\phi_{1}\left(m_{s}-m_{d}\right)+\rho \\
\Delta p & =d \Delta p+(1-d) \Delta p_{-1}^{e}
\end{aligned}
$$

\section{THE DATA}

The model described in the last section of this paper was initially estimated for the period 1954 - 1978 using annual data for the United States. However, as a further test, it was also fitted for the longer time period 1946 - 1976. This choice was prompted by the fact that Barro's (1978) well known new-classical model was fitted for this time period and, inasmuch as it deals with the behaviour of prices and output, generated results with which ours are directly comparable. In point of fact, we also estimated our model for the period 1946 - 1978, but because the extra two years of data made no significant difference to any of our results, we do not report the outcome of these particular experiments.

With one or two exceptions, our choice of data is quite straightforward. The real income varlable is gross national product, and the price level the GNP deflator. Government expenditure is represented by real purchases of 
goods and services by federal, state and local governments, while the tax rate is given by the ratio of federal state and local taxes (net of transfers) to GNP. The nominal money supply is measured by $M 2$, and this choice 1s important. The results reported below do not, in every respect, hold up if $\mathrm{MI}$ is used instead. ${ }^{8}$ We chose the three month treasury bill rate to represent the nominal interest rate in the demand for money function. "Steady state" values of real income and government expenditure were generated as simple log. linear time trends fitted to the series in question for the period 1946 - 1978. For the tax rate varlable, there seemed to be no well determined trend, so in this case we represent the steady state value of the variable by 1 ts mean. It should be noted that these measurement procedures impose the assumption of long-run crowding out upon our model. It Is also worth noting explicitly that we did a considerable amount of work to explore the consequences for our model's performance of using different time periods to generate the relevant trends and means, and confirmed that our results were not sensitive to this particular choice of period. We did not follow this procedure with the real rate of interest. Rather, in generating the results reported, we used the level of this variable, thus including its "steady state" value $\left(\phi_{0}\right)$ in the intercept of our output regression and permitting the parameter in question to be estimated.

We chose the dividend price ratio to represent the real interest rate, and did so, among other reasons, because we belleve that variations in this varlable will capture those elusive shifts in the marginal efficiency of capital to which we have referred above. If an excess supply of money was the only factor causing the real interest rate of fluctuate in a manner that had a systematic effect on aggregate demand, then its inclusion in equation (1) 
would be redundant. The $\left(m_{s}-m_{d}\right)$ term would capture all of its influence. However, if there are autonomous fluctuations in expectations about the future profitability of investment, then, for a given current rate of flow of dividend payments, these would presumably be reflected in fluctuations in stock prices, fluctuations that would occur independently of variations in monetary varlables. In that case there would be enough independent variation in the dividend price ratio for it to play a role of its own in equation (i) even in the presence there of $\left(m_{s}-m_{d}\right)$. We could think of no way of measuring these marginal efficiency of capital variations independently of the dividend price ratio, so that, in fitting equation (v) we simply treated $\rho$ as being part of the equation's error term, and used $\left(m_{s}-m_{d}\right)$ as the sole explanatory varlable in that expression.

One further comment about the real interest rate variable is in order at this point. Initially we had trouble getting equation $(v)$ to perform well, though the rest of the model was not affected by these difficulties. We were able to "cure" this problem with a little data mining. The addition of a shift dummy variable for the years 1973 onwards to this equation was all that was required to get it to perform well. To use this procedure implies that there was a sustained downward shift in the marginal efficiency of capital in 1973 that our model does not explain, but treats as exogenous. 9 A final point that needs to be made here concerns equation (iv). The relationship between real and nominal interest rates as specified there is valid for the case of assets that are otherwise identical. There are of course many differences between common stock and treasury bills apart from one being a real and the other a nominal asset. Here we attempt to capture the effects of all these difference in a constant "1iquidity premium", $\gamma_{0}$ 
which we expect to take a negative value.

A word about the timing of our data is now in order. Output, government, expenditure, and taxes are measured by annual rates of flow, measured at midyear. The money supply and interest rate variables are all end year figures, however, being averages of the $4 \mathrm{th}$ quarter observation and the 1st quarter of the following year. The price level is also an end year figure, being a 4 quarter average centered at the end of December. This choice was made so as to ensure that our results on the price equation were as comparable as posstble to Barro's and we explicitly checked to confirm that the substitution of a two quarter average made no essential difference to our results. As far as the output equation was concerned, it did not, but the use of a one year average measure of prices rather than a six month average did lead to considerable improvement in the price equation's performance. 10

\section{EMPIRICAL RESULTS}

The model set out at the end of section II of this paper cannot be estimated as it stands. Two of its equations, those determining the long run demand for money, and the expected inflation rate, have non-observable dependent variables. When these are substituted into the appropriate places; and the minor modifications discussed in the last section are made, our model reduces to a four equation system that may be set out as follows:

$$
\begin{aligned}
y= & \left(\alpha_{1} \delta_{0}-\alpha_{6}^{1} \phi_{0}\right)+\alpha_{1}\left(m_{s}-p\right)_{-1}-\alpha_{1} \delta_{1} y_{-1}^{*}-\alpha_{1} \delta_{2}^{1} R_{-1} \\
& +\alpha_{3} t-1 \\
& +\alpha_{4} g+\alpha_{6}^{1}{ }^{1}-1
\end{aligned}
$$




$$
\Delta p=\beta_{0} \Delta y_{-1}+d \beta_{0} y_{-2}+\Delta p_{-1}
$$

IIIa

OR

$$
\begin{aligned}
\Delta \mathrm{p}= & \mathrm{d} \beta_{1} \delta_{0}-\beta_{1} \delta_{1} \Delta \mathrm{y}^{*}+\beta_{1}\left(\Delta \mathrm{m}_{\mathrm{s}}-\Delta \mathrm{p}\right)_{-1} \\
& -\beta_{1} \delta_{2}^{1} \Delta \mathrm{Rn} \mathrm{p}_{-1}+\mathrm{d} \beta_{1}\left(\mathrm{~m}_{\mathrm{s}}-\mathrm{p}\right)_{-2} \\
& -\mathrm{d} \beta_{1} \delta_{1} \mathrm{y}_{-2}^{*}-\mathrm{d} \beta_{1} \delta_{2}^{1} \mathrm{Rn}_{-2}
\end{aligned}
$$

$$
\begin{aligned}
\mathrm{Rn}= & \mathrm{d} \gamma_{0}+\Delta \mathrm{R}+\mathrm{dR}_{-1}+\mathrm{d} \Delta \mathrm{p}+(1-\mathrm{d}) \mathrm{Rn} \\
\mathrm{R} & =\phi_{0}+\phi_{1} \mathrm{~d}+\phi_{2} \mathrm{D}_{1973-78}+\phi_{1}\left(\mathrm{~m}_{\mathrm{s}}-\mathrm{p}\right) \\
& +\phi_{1} \delta_{1} \mathrm{y}^{*}-\phi_{1} \delta_{2}^{1} \mathrm{Rn}
\end{aligned}
$$

Our a priori expectations about the values of the parameters of this system are as follows:

$$
\begin{gathered}
\alpha_{1}, \alpha_{4}, \delta_{1}, \beta_{0}, \beta_{1}, \phi_{0}, \phi_{2}>0 ; \\
0<d<1 ; \alpha_{3}, \alpha_{6}, \delta_{2}, \phi_{1}, \gamma_{0}<0
\end{gathered}
$$

As the reader w111 see, there are a large number of over-identifying restrictions on parameter values implicit in the above model, and it was estimated with all of these being imposed, using full information maximum likelihood programmes developed by Dr. Clifford Wymer. Table I contains the results of this exercise for the years 1954 - 1978, for versions of the model 
containing each price equation in turn.

The results presented there seem to us to be satisfactory, on the whole. It is apparent that the substitution of one price equation for another makes virtually no difference to the estimates that we obtain of the model's other parameters, and this is not a result to be taken for granted, given the extra overidentifying restrictions on the parameters of the demand for money function that the use of equation IIIb introduces into the model. ${ }^{11}$ In both versions of the model, all parameters take the sign that was a priorl expected. Furthermore, only the parameter relating output to the tax rate falls in both cases to be different from zero at conventional levels of statistical significance; but even this parameter is sufficiently large relative to its standard error that it would be unwise to dismiss the possibility that tax rate variations did have a significant short term impact on output on the 1954 - 1978 period on the basis of this evidence.

Varlations in the real rate of interest have an important effect on expenditure, even in the presence of the excess supply of money term in equation ( 1 ). However, they are themselves in part the result of a real balance effect, as the statistically significant negative value for the parameter $\phi_{1}$ Implies. This would appear to mean both that interest rate variations are an important indirect channel of monetary effects on output, but also that there are enough sources of variations in real interest rates that are not monetary to enable the parameter $\alpha \frac{1}{6}$ to be separately estimated. Th1s in turn suggests that our conjectures, about fluctuation in the marginal efficlency of capital being an independent source of variation here, may not be without foundation. 
Not only do all parameter estimates reported in Table I make qualitative sense. They make quantitative sense as well. In particular the parameters of the demand for money function are well within the range of what one might have expected on the basis of a wide range of studies - though the Implied interest elasticities do seem to be a little on the high side given some recent work (e.g., Lieberman 1980). Last but not least, the well determined values for $\alpha_{1}$ and $\phi_{1}$, not to mention $\beta_{1}$ in the second version of the model suggest that the adjustment of real balances towards their desired long run values has a pervasive and systematic influence on the macroeconomy. Such a result has already been well documented for the United Kingdom by Jonson (1976) and Laidler and O'Shea (1980), and for Australia by Jonson et al. (1976) and it is therefore of considerable interest to have such strong confirmation of the importance of real balance effect,s for the United States as well.

As we have already remarked, the next step in our investigation of the empirical properties of our model involved fitting it to data for a longer time period, namely 1946 - 1976. The results of this exercise are presented in Table 2, but before we discuss them directly, two points should be made. We have already referred to difficulties encountered in obtaining a satisfactory performance from our interest rate determining equation, and noted that the problems involved were "solved" by introducing the shift dummy parameter $\phi_{2}$ into the relationship. Similar problems were encountered with the 1946 - 1976 time period and this time two dummy variables had to be added to real interest rate equation to "solve" the problem. $\phi_{2}$ remains in the equation, as before, and $\phi_{3}$ is attached to a dummy variable that takes the value unity for 1946 - 1953 and zero therafter. ${ }^{12}$ More important, the period between 
the end of the second World War and 1953 was one in which nominal interest rates were pegged. For this period, it is nonsense to suggest that the Fisher equation (IV) represents an appropriate way of modelling the behaviour of the tresury bill rate. For those years this variable was exogenous. Hence, with appropriate use of dummy variables, we limited the period for which the parameters of equation IV were estimated to 1954 1976, simply treating the nominal interest rate as a constant $\mathrm{K}$ for earlier years.

These, as we hope the reader will agree, relatively minor modifications were the only ones undertaken in order to generate the results presented in Table 2. The most notable difference between those results and the estimates given in Table 1 lies in the parameter $\delta_{2}$, which measures the interest sensitivity of the demand for money. As we shall show later, when we discuss results obtained for our expenditure equation using ordinary least squares, this problem seems to stem at least in part from the use of a semi-logarithmic formulation of the demand-for-money - interest-rate relationship, which was adopted in the first place as an approximation designed to maintain the Iinearity of our model. Over the period 1946 - 1953 the treasury bill rate was maintained approximately constant at a level well below that ruling on average after 1953, so that the addition of these years to the data set might be expected to do particular damage here if the relevant relationship was In fact mis-specified. 13

The second point about the results presented in Table 2 worth explicit note is the strength of the fiscal policy variables. There is no doubt here about the statistical significance of tax rate changes as a short-run influence 
upon aggregate demand. The quantitative importance of this variable, and of government expenditure is also considerably greater, too much so for the comfort of anyone wishing to claim quantitative stability for the model's parameters in the face of the additional data used in the generation of Table 2. Indeed, these parameters are not the only ones whose estimates change quite a lot in the face of additional data. ${ }^{14}$ However, all parameters estimates presented in Table 2 remain of the a priori expected sign, and, are of reasonable orders of magnitude as well. Our model is at least qualitatively robust. To say this is not to claim all that much for it, perhaps, but it is more than can be claimed for many models when extra data are added to the sample for which they were originally estimated, particularly data like these, dominated by the aftermath of the second World War, and by the Korean War.

\section{A COMPARISON WITH BARRO'S MODEL}

Though the results reported above are surely strong enough to support the claim that our model should be taken seriously, they do nevertheless concern its performance taken in isolation. We are still left with the question "How strong is strong?" In this case, it is possible to face up to this question directly and compare the performance of our model with that of an alternative, widely cited, framework. Two of our dependent variables, the deviation of the $10 \mathrm{~g}$. of output from trend, and the inflation rate, are the same as those explained by Robert J. Barro's (1978) new-classical model of the United States. Barro is exceedingly thorough in his presentation of results, going so far as to present the residuals from his equations, so that a direct comparison of his residuals with ours can be made. 
Table 3 presents the relevant information for this exercise, as far as. the output equations of the two models are concerned. There the residuals from Barro's output equation as fitted by ordinary least squares, are reported In the first column, and subsequent columns report residuals from various versions of our model. In particular the second and third columns of the table present the residuals from our output equation when it is fitted as part of the complete system whose results are reported in Table 2, the first for the version of the model using an orthodox expectations augmented Phillips curve, and the second containing equation IIIB which attributed a direct role to monetary disequilibrium in influencing prices. The remaining column presents the residuals from an ordinary least squares estimate of our own equation which we shall discuss in a moment. In addition to the residuals themselves, we present statistics for their mean absolute value.

As the reader will see, as far as output equations are concerned, there is essentially nothing to choose between Barro's model and ours. Even when all the constraints implicit in the structure of the complete system are Imposed upon our output equation, its mean absolute error is bur one tenth of one percent worse than that of Barro's equation. However, the latter is an ordinary least squares estimate of a single equation taken in isolation and, furthermore, one in whose construction a distributed lag scheme was determined by the data. ${ }^{15}$ In the case of our estimate, not only was information contained in the rest of the model taken into account in arriving at it, which would tend to worsen its fit relative to that of an ordinary least squares estimate, but the extremely simple lag pattern with which the construction of the model began was maintained throughout the exercise; the lag pattern implied there was imposed upon the data. They were not permitted here to determine 1ts form. 
As we have already remarked, the last column of Table 3 contains residuals derived from an ordinary least squares estimate of our output equation, further details of which are given in Table 4. The residuals actually presented there are for a completely log. Iinear specification of the equation, set out as equation (1) above on page 4 . We did of course also fit the version of the equation using natural values of the interest rate variables by ordinary least squares, and found that the results here.were essentially the same as those generated by full information techniques. In particular the nominal interest rate did not appear to be a significant variable in the demand for money function. As the reader will see, this particular problem vanishes when a 10g. Iinear formulation is used while the goodness of fit of the log. linear relationship is also slightly better. ${ }^{16}$ The mean absolute residual from the log. linear version of our output equation is in fact the same as that generated by Barro's model, and while the absolute sum of the residuals is marginally smaller (.336 as opposed to .346) it is inappropriate to draw conclusions from this, given that the data from which these sums derive have been rounded to 3 places initially.

A word should be said about the results presented in Table 4. First, the standard error of the regression, $\sigma$, has;, as far as we know, been calculated by the same formula as Barro's and is marginally smaller than that for his equation which was .016. Second, the Durbin-Watson statistic for our equation is a "borderline" value, suggesting that auto-correlation in the residuals of our output equation is not a serious problem for the 1946 - 1976 period. This is a point of some importance, because Wymer's programmes do not contain any error term diagnostics and in this respect there must always be an element of doubt about the results that they generate. We did re-estimate our equation, 
using the Cochrane-Orcutt adjustment for the first order serial correlation, and confirmed that, for the period 1946 - 1976 there were no serious problems here. However, the reader should note that oLS estimates of the relevant equation for the 1954 - 1978 period suggest that serial correlation is a more Important problem in the shorter period, thus 1ending further support to the conclusion that we have already drawn above, namely that the robustness of our model in the face of data from various time periods lies more in its qualitative nature than in the quantitative values of its parameters. ${ }^{17}$

Even so the OLS parameter estimates of the output equation are very like those yielded the complete model, with the exception of the interest elasticity of demand for money. This suggests that much of the strength of our model's overall performance dertves from this equation, a conclusion which is partly supported by further work, not worth reporting in detall, which shows that our real interest rate determining equation generates nonsense results, of no statistical (or economic) significance, when attempts are made to estimate it in isolation. This is true for both the 1954 1978 period and for 1946 - 1976. The price equation, however, does not perform so badly in isolation, as we shall see in a moment.

Table 5 presents the residuals from Barro's price equation and various versions of ours. Its format is essentially the same as that of Table 3 and needs no extra explanation. However, it should be noted that, because Barro's data are centered at mid-year, and ours at end year, the residuals here are not strictly comparable. As the reader will see, the "complete model" form of our expectations augmented Phillips curve produces a mean absolute error that is but a tenth of a percent greater than Barro's equation, 
while our alternative formulation of the price equation improves on his by a similar margin. However, the years 1946 and 1947 produce exceptionally large residuals for Barro. That is because his price equation was actually fitted for the period 1948 - 1976, apparently because the presence of these two earlier years in his sample made nonsense of estimates of the equation for the entire period. There are two ways of judging this matter. The first is to argue that the very fact that our equation fits a sample including these earlier years shows its superiority, while the second is to suggest that, on the contrary, the comparison we make that includes residuals for 1946 and 1947 is unfair to Barro, who did not claim to be able to explain these two years in the first place. Our own model in fact fits the Korean War period particularly badly, and if we start the comparison with Barro in 1950, his equation wins easily enough, as the data show. The reader may satisfy himself that to drop the Korean War years brings our equations, particularly the simple Phillips curve, back into contention again. ${ }^{18}$

In short, just whose equation is the better here depends very much upon the choice of periods, but we would note that 1946 - 1976 is Barro's period, not ours. Moreover, we would also remind the reader that his residuals come from an equation fitted in isolation, with a rather complex lag structure generated by the data; and that Barro had considerable difficulty in reconclling the lag structures of his output and price equations when he came to fit them simultaneously by full information methods. ${ }^{19}$ Our residuals, on the other hand, come from equations estimated as part of a complete system as well as in 1solation. As the reader will see, neither of our alternative price equations gains much from being estimated in 1solation, as far as goodness of $\mathrm{fit}$ is concerned. Indeed, as the results presented in Table 6 for the 
single equation estimates of these relationships show, the parameter estimates change relatively little from those generated by the complete system. The main exception here, for the 1946 - 1976 period, is the interest elasticity of demand for money in equation IIIB which takes the wrong sign'and is very badly determined while the parameter d also presents problems of goodness of fit. It is worth noting, though, that a single equation estimate of this equation for the 1954 - 1978 period does not display these deficiencles, so that perhaps the choice of time period as well as the use of a slightly misspecified form of the demand for money function may have something to do with our difficulties in getting a well determined negative relationship here for the 1946 - 1976 period. Once again, as the reader will perhaps have concluded already, we have evidence of a certain lack of quantitative robustness in our results.

Be all that as it may, Barro's model, with which we are here comparing our results, is widely cited, and despite all its shortcomings, our model does perform about as well as his for the time period that he selected. Moreover, it does 80 without the aid of distributed lag patterns generated by the data, and having no theoretical foundation; with fewer difficulties in satisfying implicit cross equation constraints upon parameters; and while treating the nominal interest rate, which is exogenous in Barro's system, as an endogenous varlable, at least for the bulk of the period. This is not to mention the fact that, with perhaps the exception of the way in which the real balance effect is formulated, our model is little more than an empirical application of a text-book style post keynesian model, and hence should be readily accessible to anyone who has taken an intermediate macroeconomics course. 


\section{CONCLUSIONS}

The model that we have presented in this paper is an analytically simple one, and although it has fallen a good way short of perfection in its ability to explain empirical evidence, the tests to which it has been subjected have nevertheless been stringent ones. It has been tested against data for two, albeit overlapping, time periods, and has been compared in explanatory power to another, widely cited, model. Whether it may be said to have "passed" these tests 1s, in some measure a subjective matter, about which it is possible for reasonable people to differ, but we would claim that its performance has been at least strong enough to warrant taking the model seriously. Though some bits of the system have given us trouble, notably those that deal with the determination of real and nominal interest rates, and their influence on other variables, this is hardly surprising. These variables are notoriously difficult to model empirically.

We should not permit problems here to distract us from the robustness of other aspects of the model. The role of "real balance effects" in influencing output, the real rate of interest, and perhaps the inflation rate as well, gets strong support from our work, and this is all the more remarkable in that the hypotheses at stake here were originally developed using data for other. countries, the UnIted Kingdom and Australia. In this respect our results represent a "replication" of other experiments in the true sense of the word, and a successful replication at that. Moreover, our results on the Influence of fiscal policy are also worthy of special note. Here again, we were Involved In an attempt at replicating an experiment originally carried out for other countries, and again, the replication was successful. Given that when monetary 
variables have in the past been used in simple models of the United States, notably in the St. Louis model, fiscal policy has appeared to be Irrelevant as far as the determination of real income is concerned, this result is a notable one.

Whether the model we have presented here should be termed "Keynesian" or "Monetarist" is a moot point. In the importance it accords to the interaction of the supply and demand for money in determining income and prices, the latter adjective would appear to be more appropriate, but in its stress upon disequilibrium effects, and upon aggregate demand as being the prime determinant of current output, it is more in the Keynesian tradition, and this is not to mention the importance attached to fiscal policy by our results. Whatever adjective the reader may care to bestow upon it, the model is undoubtediy not in the new-classical tradition represented by the empirical work of Barro. The fact that it is more straightforward than Barro's model, and copes at least as well with the same data as does that structure, suggests that there Is as yet no pressing empirical reason to abandon traditional modes of macroeconomic analysis in favour of this radical new alternative. Perhaps that is the most important implication of the work we have presented here. 
TABLE 1

PARAMETER ESTIMATES 1954 - 1978

(a)

Model with Equation IIIa

Parameter

Value

(Figure in Parenthesis is Asymptotic Standard Error) (b)

Model with Equation IIIb

Value

(Figure in Parenthesis is

Asymptotic Standard Error)

0.469

$(0.282)$

0.815

$(0.042)$

-1.308 (Implied elasticity

$(0.369)$ at mean -0.494$)$

$(0.491)$ at mean -0.316$)$

0.327

$(0.053)$

0.322

$(0.053)$

$-0.063$

$(0.046)$

$(0.048)$

0.131

$(0.043)$

$-2.085$

(0.305)

0.266

$(0.091)$

Bo

${ }^{B} 1$

d

0.266

$(0.091)$

0.034

$(0.001)$

0.145

$(0.043)$

$-1.915$

(0.295)

$-0.061$

$(0.021)$

0.012

$(0.003)$

$-0.025$

$(0.010)$
0.319

$(0.060)$

0.195

$(0.082)$

0.034

$(0.001)$

$-0.049$

$(0.021)$

0.014

$(0.002)$

$-0.016$

(0.015) 
TABLE 2

PARAMETER ESTIMATES 1946 - 1976

(a)

Model with Equation IIIa

\section{Parameter}

$\delta_{0}$

$\delta_{1}$

$\delta_{2}^{1}$

$\alpha_{1}$

$\alpha_{3}$

$\alpha_{4}$

$\alpha_{6}^{1}$

$\beta_{0}$

$\beta_{1}$

d

$\phi_{0}$

$\phi_{1}$

$\phi_{2}$

$\phi_{3}$
Value

(Figure in Parenthesis is Asymptotic Standard Error)

1.635

$(0.312)$

0.636

$(0.049)$

$-0.027$

$(0.702)$

0.323

$(0.039)$

$-0.184$

$(0.041)$

0.339

$(0.030)$

$-1.189$

$(0.297)$

0.288

$(0.132)$

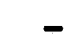

0.402

$(0.117)$

0.034

$(0.001)$

$-0.038$

$(0.012)$

0.008

$(0.002)$

0.024

$(0.002)$ (b)

Model with Equation IIIb

Value
(Figure in Parenthesis is
Asymptotic Standard Error)
1.495
$(0.248)$
0.659
$(0.038)$
-0.406
$(0.419)$
0.321
$(0.038)$
-0.183
$(0.040)$
0.335
$(0.030)$
-1.173
$(0.290)$
-

0.610

(0.108)

0.102

$(0.053)$

0.034

$(0.012)$

$-0.036$

$(0.014)$

0.010

$(0.003)$

0.024

$(0.002)$ 
Table 2 (Continued)

Parameter

(Figure in Parenthesis is Asymptotic Standard Error)
Value

(Figure in Parenthesis is Asymptotic Standard Error)

$-0.012$

$(0.024)$

0.012

$(0.004)$ 
TABLE 3

\begin{tabular}{lll}
\multicolumn{2}{c}{ "Complete" Model } & \\
Barro With Equation IIIa & With Equation IIIb & Laidler - \\
\end{tabular}

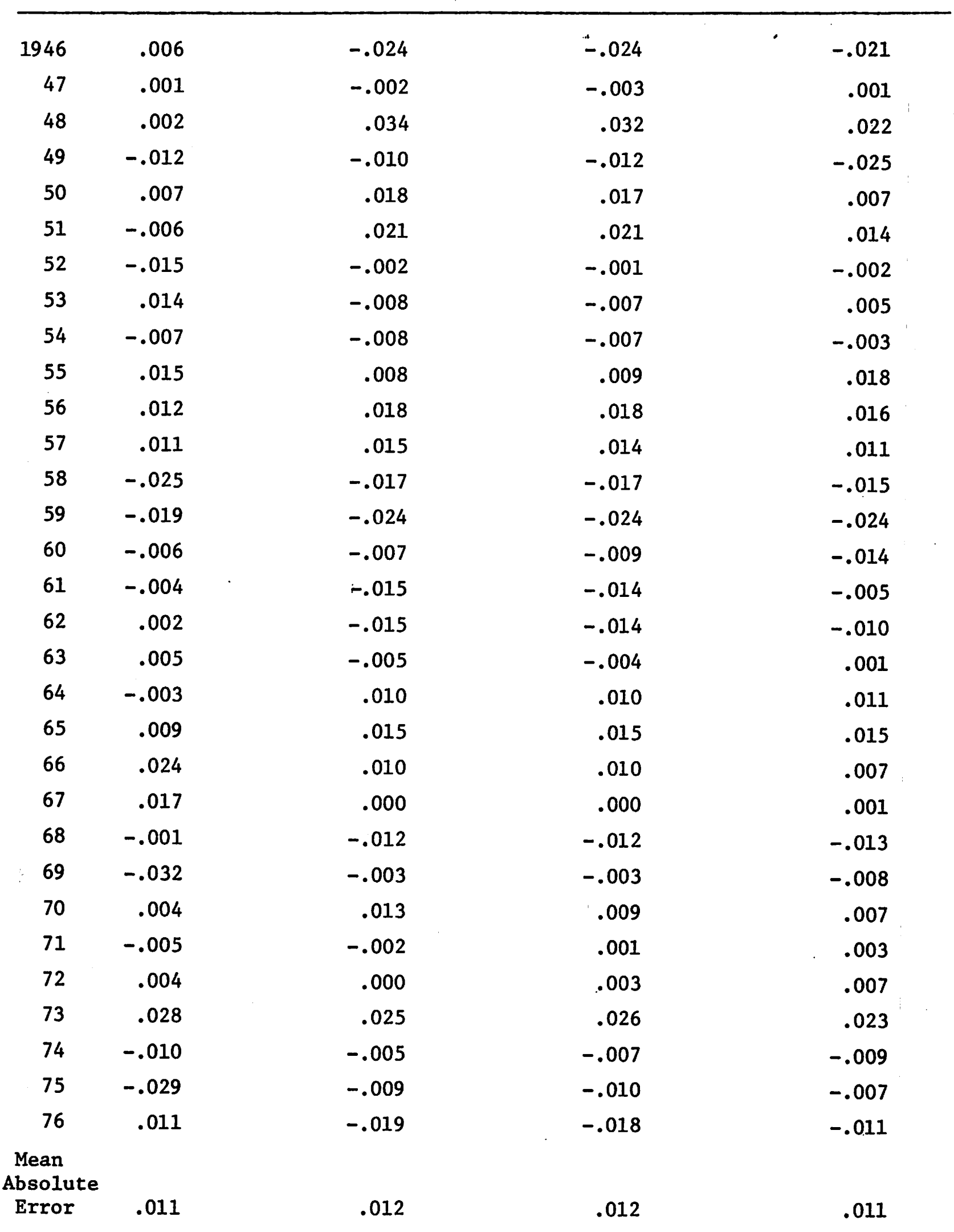


TABLE 4

PARAMETERS OF THE OUTPUT EQUATION 1946 - 1976, AND 1954 - 1978

AS FITTED BY CONSTRAINED LEAST SQUARES*

FIGURES IN PARENTHESES ARE ASYMPTOTIC STANDARD ERRORS,

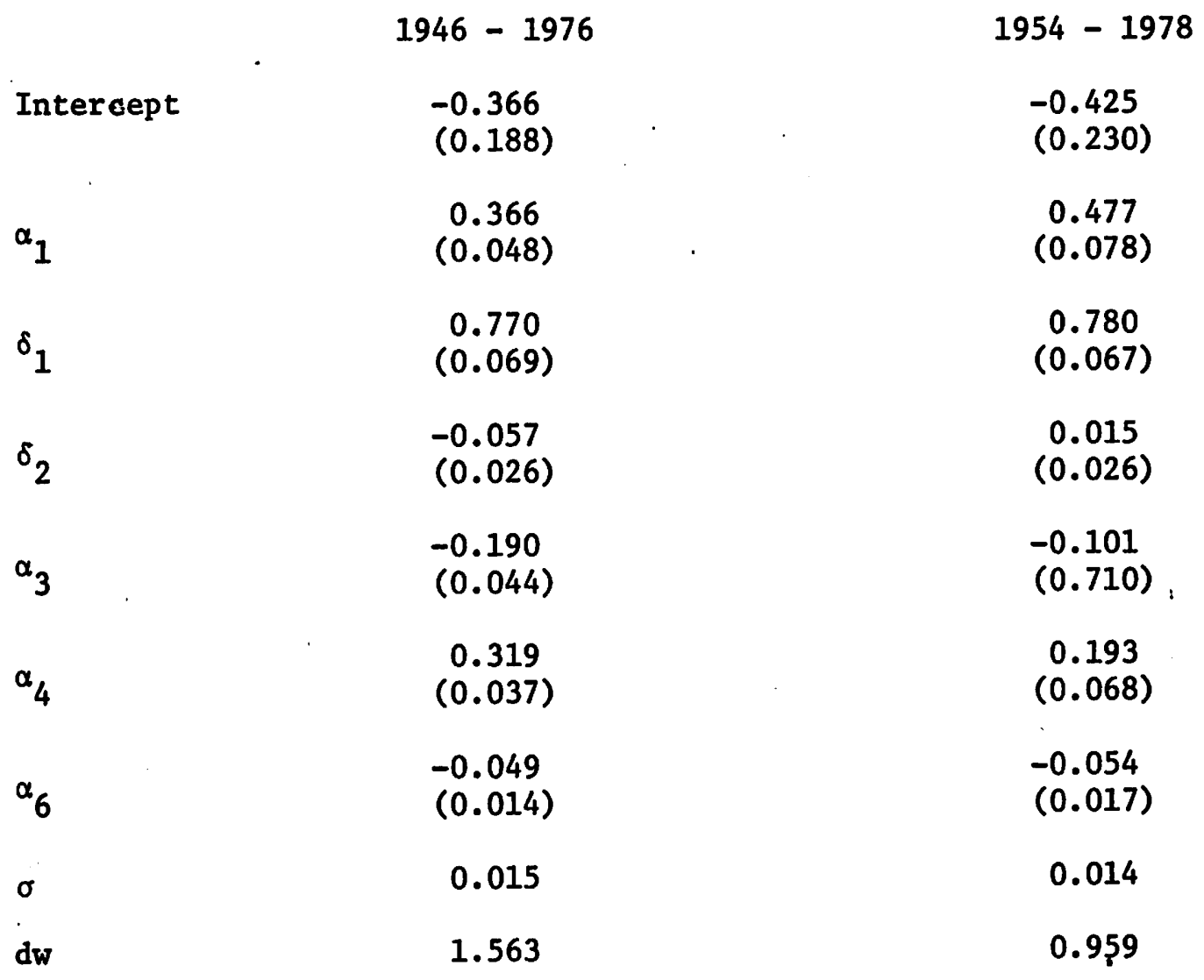

* Note that these results are for a completely log. linear form of the equation, and that the parameter having to do with interest rates are not comparable to those presented in Tables 1 and 2 . 
TABLE 5

"Complete" Model Laidler - Bentley OLS With With Barro Equation IIIa Equation IIIb Equation IIIa Equation IIIb

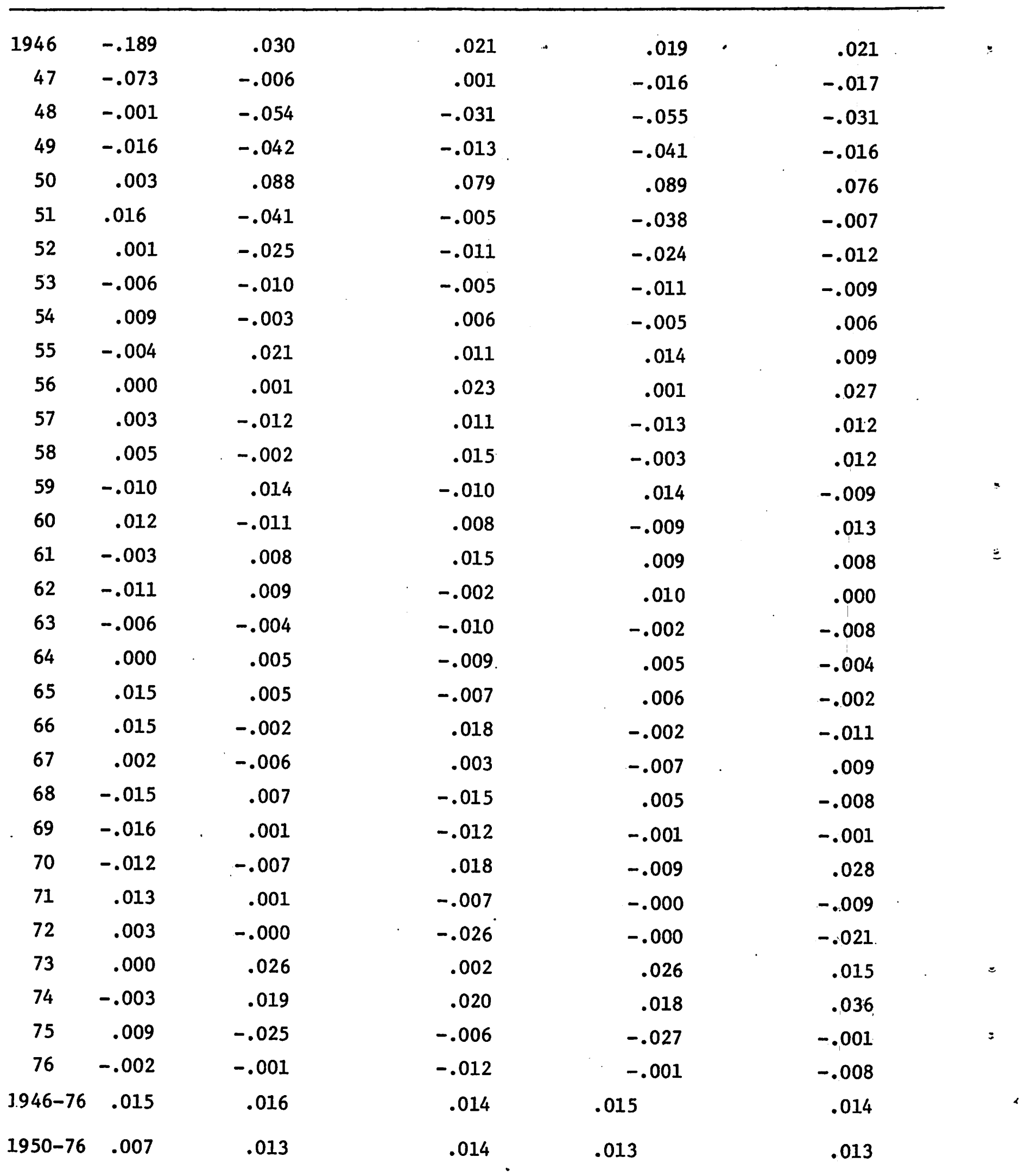


TABLE 6

\begin{abstract}
PARAMETERS OF PRICE EQUATING 1946 - 1976, 1954 - 1978
AS FITTED BY CONSTRAINED LEAST SQUARES*

FIGURES IN PARENTHESES ARE ASYMPTOTIC STANDARD ERRORS
\end{abstract}

A. Equation IIIa

$\begin{array}{ccc} & 1946-1976 & 1954-1978 \\ \beta_{0} & 0.283 & 0.308 \\ & (0.137) & (0.101) \\ \text { d } & 0.558 & 0.179 \\ \sigma & (0.240) & (0.242) \\ \text { dw } & 0.025 & 0.030 \\ & 2.333 & 2.216\end{array}$

B. Equation IIIb

$\begin{array}{lcc}\text { Intercept } & -0.169 & 0.030 \\ & (0.120) & (0.065) \\ \beta_{1} & 0.570 & 0.351 \\ & (0.136) & (0.081) \\ d & 0.079 & 0.239 \\ & (0.075) & (0.144) \\ \delta_{1} & 0.875 & 0.916 \\ \delta_{2} & (0.431) & (0.100) \\ \sigma & 0.006 & -0.048 \\ d w & (0.023) & (0.025) \\ & 0.021 & 0.010 \\ & 2.098 & 2.088\end{array}$

* Note that these results are for a completely log. 1inear form of the equation, and that the parameter having to do with interest rates are not comparable to those presented in Tables 1 and 2 . 


\section{FOOTNOTES}

1. The output equation which we are about to discuss is closely related to that used by. Laidler and O'Shea (1980) in their small model of the U.K. economy under fixed exchange rates. A version of it, that did not include fiscal policy variables, was also used by Laidler (1980) to explain quarterly U.S. data.

2. The precise procedure is described by Wymer (1976).

3. However, for purposes of our empirical work, long run crowding out is Imposed by the way in which we measured the "Steady state" values of the relevant variables. It is worth noting that in the work of Jonson and his varlous associates on the RBA 76 model of the Australian economy, the steady state properties of the system are generated by what amounts to a neoclassical growth model embedded in the system. That model, of course, is far more complex than the one we present. See Jonson, Moses and Wymer (1976).

4. The reader might note that the parameter $\alpha_{5}$ was reserved for this lagged dependent variable in our work, and that is why it does not appear in the version of the model presented. Similarly $\alpha_{2}$ has been reserved for future use to investigate terms of trade effects on aggregate demand.

5. See, for example, Bergstrom and Wymer (1974), Jonson (1976), Jonson, Moses and Wymer (1976), Laidler and O'Shea (1980), Laidler (1980). 
6. These alternative interpretations of the Phillips curve have been discussed by Laidler (1978).

7. We will discuss the problems raised by mixing logarithms and natural values of interest rates in our system in due course.

8. Using MI, we are unable to get well determined estimates of the real permanent income elasticity of demand for money from our system, though other elements of the output equation hold up. We suspect that this problem. arises from our choice of trend real income as the scale variable in our demand for real balances function. This is a very "long run" variable, and Meyer and Ner1 (1975) have suggested that the demand for MI: is: more closely: related to current transactions. Note that Laidler (1980) reports similar problems when using quarterly data.

9. An alternative interpretation of this. "shift" is that there was a change In the steady state value of the real interest rate in 1973. In that case, it. would be approprlate to add the same shift dummy to the intercept of equation $I$. We did experiment along these lines, and found that very. little difference was made to our results by doing this, though the significance of the real interest rate as an argument in the output equation was affected. particularly when the equation was estimated in isolation by ordinary least squares.

10. From 1947 till 1978 our price level variable is a four quarter average quarterly values of the deflator. For earlier years it is a: two year average of annual observations, because quarterly data were not available, 
and our data needed to be centered at end year. This only effects one or two observations when we apply our model to the longer of the two periods for which it was estimated.

11. The reader should note that we did try a form of the model in which the parameters $\beta_{0}$ and $\beta_{1}$ appeared simultaneously in the price equation, but that in this case $\beta_{0}$ effectively disappeared from the system. Thus, it is possible to argue that version $B$ of our model is the one better supported by the data.

12. The reader should note that the arguments presented in footnote \#9 are equally relevant here, and that similar experiments with dummies to those described there were carried out for this longer time period, and with similar results.

13. The reader might note that, if the rate of interest vanishes from our demand for money function, it becomes possible to eliminate equation IV from our system. We also experimented with dropping both interest rate variables altogether. In that case Equations $I$ and III themselves form a real income and price determining model that is a special case of the more elaborate system being described here. In fact such a simplified model performs quite well, with the parameters of remaining variables changing very little when the interest rates are removed. However, the model does lose explanatory power.

14. The intercept of the demand for money function $\delta_{0}$ changes a good deal with the addition of the earlier years. Any variable omitted from the 
model that has a non-zero average effect on output, would have its effects taken up in this parameter because of the way we estimate it.

15. According to Barro's results, "unanticipated" money takes three years to have its full effects on output, and about a further year to have all its effects on prices.

16. But unfortunately, the output equation when estimated in $10 \mathrm{~g}$. 1inear form for the 1954 - 1978 period produces an insignificant coefficient on the $\log$. of the nominal interest rate. We must, therefore, conclude that the demand for money-interest rate relationship is one of the more fragile ones in our model.

17. We currently have the whole matter of serial correlation in the residuals from our output equation under investigation, and hope to report on this matter further either in a later draft of this paper, or in a further note, depending upon the nature of our findings.

18. And the reader might note that Barro's model fits the years 1973 1974, when the OPEC price shock was coming through, suspiciously well for, system that pays no attention to this event.

19. Indeed, Barro's results, taken at face value, tell us that "anticipated" money, 1.e., that which is expected to be created, has an instantaneous effect on prices, while that which is known to exist already takes four years to change prices, if its creation was not foreseen. Perhaps we are not alone in finding these implications of his results peculiar. 


\section{REFERENCES}

Barro, R. J. (1978). "Unanticipated Money, Output and the Price Level in the United States". JPE, 86 (August), $549 \pm 581$.

Bergstrom, R., and Wymer, C. (1974). "A Model of Disequilibrium Neoclassical Growth and Its Application to the United Kingdom". In Bergstrom, R. (ed.) Statistical Inference in Continuous Time Econometric Models. Amsterdam, North Holland.

Cagan, P. (1980). "Reflections on Rational Expectations". JMCB, 12 (November, Part 2), $826-832$.

Chow, G. (1966). "On the Long Run and Short Run Demand for Money". JPE, 74 (Apri1), $111-131$.

Clements, K. W., and Jonson, P. D. (1979). "Unanticipated Money, Disequilibrium Modelling and Rational Expectations". Economic Letters, 2, 303 308.

Jonson, P. D. (1976). "Money and Economic Activity in the Open Economy". JPE, 84 (October), $979-1012$.

Jonson, P. D., Moses, E. R., and Wymer, C. R. (1976). "A Minimal Model of the Australian Economy". Research Discussion Paper 7601, Sydney. Reserve Bank of Australia.

Laidler, D. (1975). "Essays on Money and Inflation". Manchester, University of Manchester Press, Chicago, University of Chicago Press.

Laidler, D. (1978), "Money and Money Income, An Essay on the Transmission Mechanism". Journal of Monetary Economics, 4 (June), 151 - 191.

Laidler, D. (1980). "The Demand for Money in the United States Yet Again". In Brunner, K. and Meltzer, A. H. (eds.), The State of Macroeconomics Carnegie Rochester Conference on Public Series, Vol. 12. 
Laldler, D. and O'Shea, P. (1980). "A Small Macromodel of An Open Economy under Fixed Exchange Rates: The United Kingdon 1954 - 1970". Economica, NS 47 (May), 141 - 158.

Lieberman, C. (1980). "The Long-Run and Short Run Demand for Money Revisited". JMCB, (February), 43 - 57.

Meyer, P. A. and Ner1, J. A. (1975). "A Keynes-Friedman Money Demand Function". AER, 65 (September), $610-623$.

Tobin, J. (1980). "Are New Classical Models Plausible Enough to Guide" Pollcy". JMCB, 12 (November, Part 2), 788 - 799.

Wymer, C. R. (1976). "Linearization of Non-linear Systems - Supplement \# 15". Computer Programs, London School of Economics. Mimeo. 